\title{
AQUAPORINAS 3 APLICADAS A COSMETOLOGIA EM REGIÃO DE FACE DE MULHERES: UMA REVISÃO DE LITERATURA
}

\author{
Aline Dantas Santos ${ }^{1}$ \\ Dirlan Vitoria Ferrari de Sena ${ }^{2}$ \\ Douglas Fernando Rambo ${ }^{3}$
}

RESUMO: Introdução: $\mathrm{Na}$ atualidade, a hidratação cutânea é fundamental para a manutenção da aparência jovem, saudável e viçosa das mulheres. $O$ processo de hidratação dos tecidos é executado pelas funções do nosso próprio organismo, juntamente com a água ingerida. A água é responsável por promover a hidratação da pele através das camadas inferiores - da derme para epiderme - sendo transportadas através dos queratinócitos pelos canais proteicos. Estes canais responsáveis pelo transporte de água pelas camadas da pele são conhecidos como aquaporinas 3 , que se trata de uma proteína, estando presente na membrana plasmática dos queratinócitos. Objetivo: Este trabalho teve como objetivo realizar uma revisão da literatura sobre os benefícios das Aquaporinas 3 aplicadas a cosmetologia em região de face de mulheres. Método: Para tal objetivo, foi elaborado um estudo com base em artigos científicos, a partir de 2010, com bases de dados eletrônicos PubMed e Google Acadêmico, onde foram consultados artigos originais e de revisão sobre o tema Aquaporinas. Resultados: A partir da revisão realizada verificou-se que a descoberta dos canais de aquaporinas 3 trouxe importantes contribuições para compreender os mecanismos envolvidos na hidratação da pele, proporcionado um aspecto saudável através da passagem de água mediada por esses poros. Evidenciou-se, também, que houve um grande avanço tecnológico, existindo a necessidade de desenvolver princípios ativos que atuam na manutenção destes canais aumentando a expressão e as atividades das aquaporinas 3 na membrana celular, restaurando a hidratação da pele e revitalizando-a. Conclusão: Observou-se que as aquaporinas 3 contribuem de maneira significativa para a hidratação da

\footnotetext{
I Graduação em Farmácia. Instituição de Ensino: Universidade Salvador (UNIFACS). Email: aline_dantası@hotmail.com.

2 Graduação em Farmácia. Instituição de Ensino: Universidade Salvador (UNIFACS). Email:dirlanferrari@gmail.com.

3 Graduado Farmacêutico Industrial pela Universidade Regional Integrada do Alto Uruguai e das Missões (2008). Possui Mestrado (2011) e Doutorado (2018) em Ciências Farmacêuticas pela Universidade Federal do Rio Grande do Sul; atuando nas áreas de química de produtos naturais, desenvolvimento e validação de métodos analíticos para controle de qualidade de matéria-prima vegetal. Atuou como colaborador na elaboração / revisão de monografias de plantas medicinais para a Farmacopeia Brasileira (ANVISA). Foi professor na Universidade Regional Integrada do Alto Uruguai e das Missões (Erechim/RS) e no Centro Universitário FADERGS (Porto Alegre/RS). Atualmente é Coordenador do Curso de Farmácia e do Curso de Estética e Cosmética na Universidade Salvador (UNIFACS - BA) e Professor Adjunto da Universidade Federal da Bahia-UFBA. Tem experiência na área de Farmácia, com ênfase em Farmacognosia, Química de Produtos Naturais, Controle de Qualidade, Farmacologia e Cosmetologia. E-mail: douglas.rambo@unifacs.br
} 
pele, porém se faz-se necessário o uso de ativos que favorecem seu aparecimento nas células cutâneas, melhorando a hidratação devido o envelhecimento cutâneo.

Palavras- chave: Aquaporinas. Cosmético. Mulheres. Pele.

ABSTRACT: Introduction: Currently, skin hydration is essential for maintaining the young, healthy, and lush appearance of women. The tissue hydration process is due to the functions of our own organism, together with the water ingested. Water is responsible for promoting the hydration of the skin through the lower layers - from the dermis to the epidermis - being transported through the keratinocytes through the protein channels. These channels responsible for transporting water through the skin layers are known as aquaporins 3 , which is a protein, present in the keratinocyte plasma membrane. Objective: This study aimed to conduct a literature review on the benefits of Aquaporins 3 applied to cosmetology in the face region of women. Method: For this purpose, a study was prepared based on scientific articles, starting in 2010, with electronic databases PubMed and Google Scholar, where original and review articles on the topic Aquaporins 3 were consulted. Results: From the review performed, it was found that the discovery of aquaporin 3 channels brought important contributions to understanding the mechanisms involved in skin hydration, providing a healthy aspect through the passage of water mediated by these pores. It was also evident that there was a great technological advance, with the need to develop active principles that act in the maintenance of these channels by increasing the expression and activities of aquaporins 3 in the cell membrane, restoring skin hydration and revitalizing it . Conclusion: It was observed that aquaporins 3 contribute significantly to the hydration of the skin, but it is necessary to use assets that favor its appearance in skin cells, improving hydration due to skin aging.

Keywords: Aquaporins, Cosmetics, Women, Skin.

\section{INTRODUÇÃO}

$\mathrm{Na}$ atualidade, as mulheres se preocupam muito com a estética facial, buscando tratamentos que proporcionem melhor aparência para a pele visto que se trata do órgão mais exposto ao ambiente externo, tornando-a mais suscetível ao envelhecimento (STADNICK; MÜLLER, 2019). Nesse sentido uma descoberta recente trouxe um forte aliado para a hidratação da pele, que pode combater e retardar o aparecimento das linhas de expressão e outros sinais de envelhecimento que vão surgindo com o tempo, essa descoberta se trata do 
uso das aquaporinas 3 em produtos cosméticos, com o objetivo de melhorar a aparência da pele através da hidratação das camadas inferiores (KAMIZATO; BRITO, 20I4).

Nos anos 9o um grupo de pesquisadores liderado por Peter Agre desvendou o primeiro grupo de canais de aquaporinas localizado na membrana plasmática das células. Descoberta que lhe rendeu o Prêmio Nobel de Química em 2003 e abriu um vasto campo de pesquisas para estudo desses canais (DRAELOS, 20II). Atualmente, existem aproximadamente treze tipos de aquaporinas no corpo humano, cada uma delas responsável por uma determinada função em seus respectivos órgãos do corpo, sendo a aquaporina 3 a responsável pelo tecido tegumentar (IKARASHI, et al., 2017).

A pele jovial apresenta maciez, brilho e toque suave devido à grande presença de água nas camadas da pele. Com a diminuição da barreira cutânea, a pele fica ressecada devido à perda de água, e consequentemente, fica desidratada. Outro fator que influencia é o estado de saúde da pele, que sofre interferência pelos fatores climáticos, patologias, baixa ingestão de água, o desequilíbrio das camadas da epiderme e o fator natural de hidratação (NMF) (AGOSTINI, 2010).

A água presente na epiderme é decorrente da derme, que chega à sua superfície por meio de difusão. Nesta camada encontramos os glicosaminoglicanos, que são responsáveis pela manutenção hídrica dessa camada da pele. Os canais proteicos - aquaporinas - ficam localizados nos queratinócitos da epiderme realizando o controle do fluxo de água, pois os queratinócitos são enrijecidos, impedindo a passagem dela em sua membrana plasmática, formando assim, uma camada lipídica (COSTA et al.,2010).

Diante dos expostos, o presente trabalho tem como objetivo realizar uma revisão da literatura sobre os benefícios das aquaporinas 3 aplicadas a cosmetologia em região de face de mulheres, analisando o seu papel e regulação bem como avaliar como os princípios ativos atuam na sua estimulação.

Dessa forma, o tema abordado é de grande relevância social, tendo em vista que a pele hidratada com aspecto jovial e bonita na região da face para as mulheres tem funções estéticas e simbólicas, considerando que a aparência, o contato a sensibilidade da pele e o emocional envolvidos, traz a elas o bem estar físico, mental e social, podendo-se julgar que o psicofisiológico e psicossocial da mulher é dependente de sua aparência exterior e da 
aceitação das características de sua face pelos demais componentes ao seu redor. Portanto, o presente trabalho tem como objetivo discutir os benefícios das aquaporinas 3 aplicadas a cosmetologia em região de face de mulheres.

\section{OBJETIVOS}

\section{I OBJETIVO GERAL}

Realizar uma revisão da literatura sobre os benefícios das Aquaporinas 3 aplicadas a cosmetologia em região de face de mulheres.

\subsection{OBJETIVOS ESPECÍFICOS}

- Identificar através de estudos científicos os benefícios das aquaporinas 3 para hidratação da pele.

- Analisar como ocorre regulação de aquaporinas 3 na epiderme;

- Avaliar como os princípios ativos atuam na estimulação dos canais de aquaporinas

\section{METOdOlOGiA}

Esse estudo trata-se de uma revisão de literatura sistemática que foi realizada entre o ano de 2020 e 2021, construído através do levantamento de dados encontrados na literatura já existente. Todos os dados levantados para o estudo foram coletados de pesquisas bibliográficas com bases de dados eletrônicos como: PubMed e Google Acadêmico, onde serão consultados artigos originais e de revisão sobre o tema Aquaporinas. Foram utilizados como descritor os unitermos "aquaporinas", "cosméticos”, "mulheres” e "pele”, nos idiomas português, inglês e espanhol. Após levantamento inicial, análise de títulos, leitura de resumos e exclusão das duplicatas, os artigos selecionados foram criticamente analisados.

Como critério de inclusão foram utilizados somente os artigos com publicação a partir de 2010 e sendo excluídos artigos anteriores a esta data. Como critério de exclusão foram retirados artigos que não contemplem na íntegra o tema proposto, bem como publicações cujos artigos não sejam publicados em revistas indexadas. Para tal estudo, traçou-se como objetivo, os benefícios da aquaporinas 3 aplicadas a cosmetologia em região de face de mulheres, analisando o seu papel e regulação bem como avaliar como os princípios ativos atuam na sua estimulação. A pesquisa foi realizada no período de Agosto de 2020 a Julho de 2021. 


\section{RESULTADOS E DISCUSSÕES}

A pesquisa foi desenvolvida de acordo com a metodologia proposta, utilizando como estratégia de busca a palavra-chave "aquaporinas 3" combinada com "benefícios para pele, "hidratação da pele" ou "epiderme". A coleta de dados se deu principalmente através das plataformas Google Acadêmio e PubMed. Foram encontrados cerca de 88 resultados relacionados com os objetivos do trabalho, que após a aplicação dos critérios de exclusão e inclusão, foram selecionados 22 trabalhos para leitura na íntegra (Figura I).

Figura I - Fluxograma de prospecção
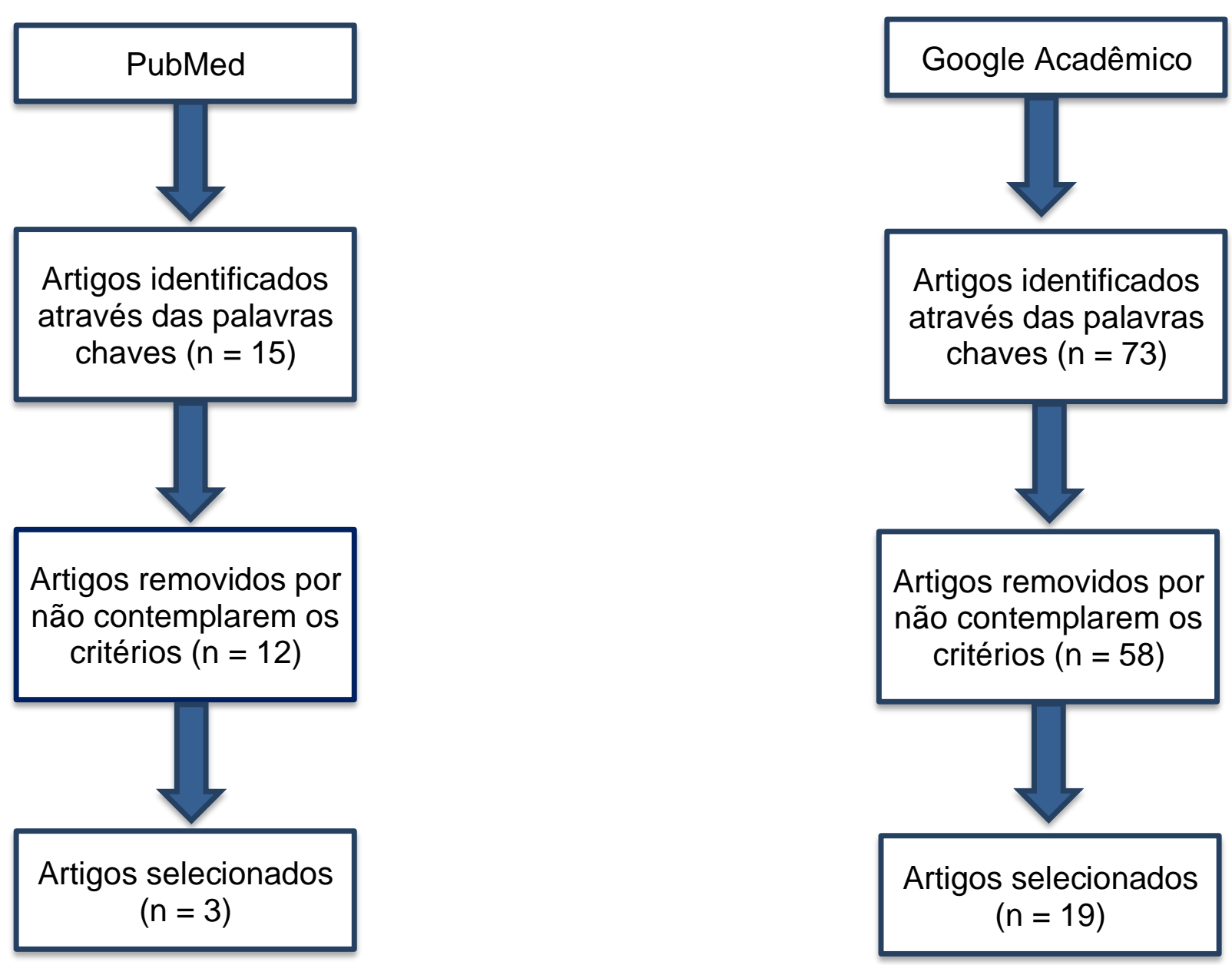

Fonte: Próprio Autor, 2021

\section{I IDENTIFICAR OS BENEFÍCIOS DAS AQUAPORINAS 3 NA HIDRATAÇÃO}

\section{DA PELE}

A pele é o maior órgão do corpo humano e é responsável por inúmeras funções fundamentais para a vida, como regulação da permeabilidade da água além de funcionar 
como barreira de proteção contra agressões ambientais (AMARAL; SOUZA, 2019). Composta por três camadas: epiderme, derme e hipoderme, sendo a derme e a epiderme importantes para o processo de hidratação natural, estando estas interligadas e complementando as suas funções (BOLLAG, et al, 2020).

Dentre estas funções, no que tange à hidratação, a derme age como um reservatório de água, ficando responsável pelo equilíbrio da pele, facilitando sua hidratação através de redes capilares e vasos sanguíneos, fornecendo nutrição a epiderme, além de agir na termorregulação e cicatrização da pele (MICHALUN, 2010). Quanto a epiderme, ela apresenta a função de proteção e retorno de líquidos, evitando a desidratação da pele, que é ocasionada pela diminuição da função de barreira do extrato córneo que modifica o cimento intracelular, alterando a permeabilidade cutânea, consequentemente, a descamação da pele (SANTOS, 2010).

A água é o componente vital para um bom desempenho fisiológico e manutenção da epiderme, porém o seu teor na pele está condicionado a interferência através da perda de água transepidérmica (TEWL) onde corre perda de moléculas de água para a atmosfera através do processo de difusão e evaporação, mecanismo natural, que pode ser influenciado pelo envelhecimento cutâneo um efeito gradual que está relacionado determinação genética e agressões externas como hábitos alimentares, a poluição atmosférica e a exposição solar (YULIANTI L, et al., 20i6) .

O envelhecimento cutâneo reduz a hidratação da superfície da pele torna a pele seca, opaca e áspera, favorecendo a perda da elasticidade, resultando em uma e aparência flácida o que traz consequências no comportamento social pois a aparência da pele está fortemente ligada a autoestima, especialmente em mulheres, que estão sempre em busca de tratamento que previnam ou revertam o envelhecimento cutâneo (DRAELOS, 2012; AMARAL e SOUZA 2019). Nesse sentido uma descoberta recente mencionada na literatura, os canais de água aquaporinas 3 encontrados na pele, constitui um novo alvo terapêutico chave no processo de hidratação cutânea (GÓMEZ e IRUSTA, 2013; BOLLAG, et al, 2020).

As aquaporinas 3 são os canais proteicos mais abundantes na pele, localizados especificamente na membrana plasmática dos queratinócitos epidérmico, atuam formando poros na membrana plasmática das células, porém atualmente existem 13 tipos identificados (AQPo-AQPI2) (DRAELOS, 2012). Estes canais também denominados aquaglicoproteínas 
permitem aumentar a permeabilidade de água na membrana plasmática das células como também de pequenas moléculas como o glicerol e agindo como regulador central, proporcionando hidratação e condições saudáveis a epiderme (BOLLAG,2020).

As aquaporinas 3 são os canais proteicos mais abundantes na pele, localizados especificamente na membrana plasmática dos queratinócitos epidérmico, atuam formando poros na membrana plasmática das células (DRAELOS, 2012). Estes canais também denominados aquaglicoproteínas permitem aumentar a permeabilidade de água na membrana plasmática das células como também de pequenas moléculas como o glicerol e agindo como regulador central, proporcionando hidratação e condições saudáveis a epiderme (Figura 2) (BOLLAG,2020).

Figura 2 - Mecanismo de hidratação da pele mediado por aquaporinas 3

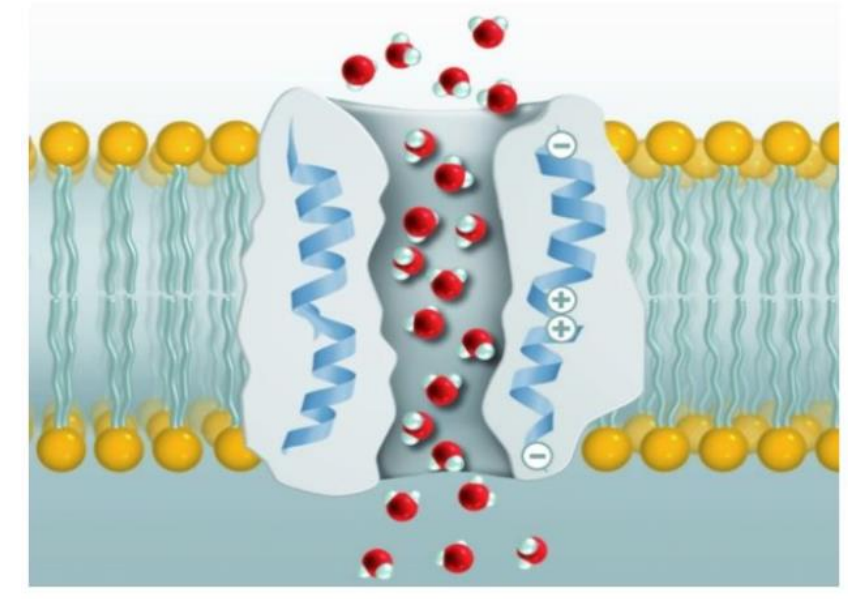

Fonte: Draelos (2012)

Dentre as principais funções no que tange a hidratação da pele e sua relação com as aquaporinas 3 destaca-se dois principais fatores: o transporte de água mediados pelos seus canais permite a retenção de umidade e manutenção do teor de água da epiderme, além de permitir o transporte de água da derme para a camada mais externa da epiderme trazendo desse modo um equilíbrio fisiológico da pele e o transporte de glicerol umectante endógeno que oferece elasticidade cutânea, facilita o reparo da barreira epidérmica, influência na composição lipídica e metabolismo do estrato córneo (DRAELOS, 2012; JUNGERSTED et, al, 2013; TITO et. Al. 2015). Tais fatores permitem a hidratação da pele melhorando a sua aparência, diminuindo rugas e a aparecia envelhecida além de auxiliar no processo de 
cicatrização de feridas, deixando pele com aspecto suave, macia e uniforme ao toque (AMARAL e SOUZA, 2019; YULIANT, et al., 2016).

\section{2 ANALISAR O PAPEL E REGULAÇÃO DE AQUAPORINAS 3 NA EPIDERME}

Os canais de aquaporinas 3 encontra-se expresso nos queratinócitos basais onde possui sua maior concentração, que vai diminuindo a medida que se aproxima do estrato córneo onde desaparece a sua expressão, o glicerol presente nas camadas externas da epiderme se liga e retém a água, mantendo a hidratação ideal da pele, como também age aumentando o metabolismo lipídico, melhorando a função de barreira do estrato córneo (Figura 3) (GÓMEZ; IRUSTA, 2016). Segundo Bollang e colaboradores (2020), os mecanismos que regulam a expressão desses canais ainda não estão totalmente definidos, mas estudos recentes em camundongos demostram que a expressão das aquaporinas 3 pode ser induzida pela inibição de enzimas de histonas-desacetilases em queratinócitos, que através da sua atuação removem o grupo acetil, adicionados por histonas-acetiltransferases, de histonas como também de proteínas, resultando em uma estrutura de cromatina relaxada, resultando em uma maior transcrição do mRNA das aquaporinas 3 .

Figura 3 - Mecanismo de hidratação da pele mediado por aquaporinas 3

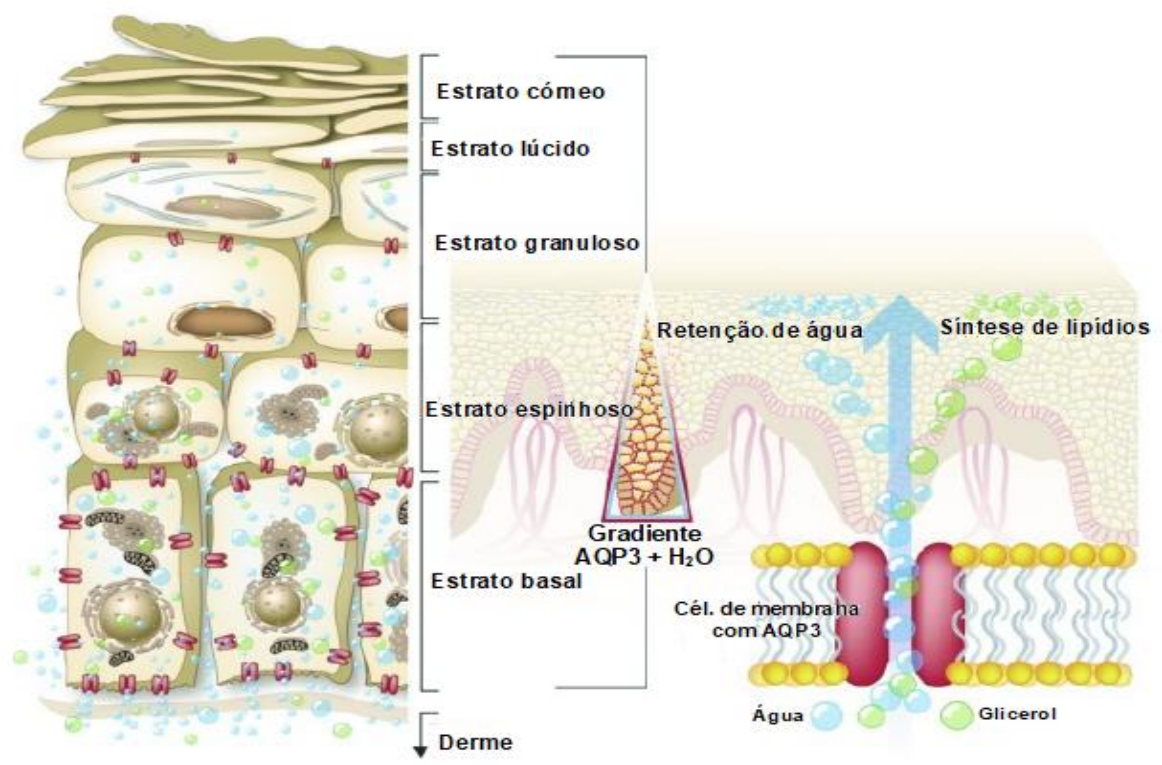

Fonte: Adaptado de Draelos (2012). 


\section{3 AVALIAR COMO OS PRINCÍPIOS ATIVOS ATUAM NOS CANAIS DE AQUAPORINAS 3 AUXILIANDO NA HIDRATAÇÃO DA PELE}

Com a descoberta das aquaporinas houve um grande avanço tecnológico, desenvolvendo cosméticos com princípios ativos que atuam na manutenção destes canais, aumentando as atividades das aquaporinas 3 na membrana celular e consequentemente o transporte de água da derme para a epiderme, restaurando a hidratação da pele e revitalizando-a (HAMMAN; MIRA, 20I6).

Apesar da pele possuir os canais de aquaporinas 3 como um grande aliado na hidratação, faz-se necessário o uso de ativos farmacológicos (Tabela I) que atuem aumentando a expressão, pois o envelhecimento cutâneo causa a sua diminuição através da interferência dos queratinócitos, tornando a pele áspera e com linhas de expressão (DRAELOS, 2012).

Tabela I - Matérias primas com de ativos farmacológico que possuem ação comprovada nos canais de aquaporinas 3: forma farmacêutica e mecanismo de ação.

\begin{tabular}{|c|c|c|c|}
\hline $\begin{array}{c}\text { Fontes de ativos } \\
\text { farmacológicos } \\
\text { com atuação na } \\
\text { aquaporina 3 }\end{array}$ & $\begin{array}{c}\text { Forma } \\
\text { farmacêutica }\end{array}$ & Mecanismo de ação & Referências \\
\hline Rosa chinesa & $\begin{array}{c}\text { Extrato de pó } \\
\text { de cultura }\end{array}$ & $\begin{array}{l}\text { Aumentou a expressão } \\
\text { da aquaporina 3 } \\
\text { regulando a hidratação }\end{array}$ & Pressi, et. al., 2019 \\
\hline Semente de chia & $\begin{array}{c}\text { Extrato } \\
\text { etanólico }\end{array}$ & $\begin{array}{l}\text { Aumento da expressão } \\
\text { das aquaporinas 3 em } \\
\text { queratinócitos }\end{array}$ & Huber, et. al., 2020 \\
\hline Alcacuz & Solução & $\begin{array}{l}\text { Promove proliferação, } \\
\text { migração e expressão da } \\
\text { aquaporina 3 em } \\
\text { queratinócitos }\end{array}$ & Hung, et. al., 2017 \\
\hline Astaxantina & Creme & $\begin{array}{l}\text { Aumento da expressão } \\
\text { das aquaporinas 3 }\end{array}$ & Ikarashi, et. Al, \\
& 202o \\
\hline
\end{tabular}




\begin{tabular}{|c|c|c|c|}
\hline $\begin{array}{l}\text { Semente de Green } \\
\text { Coffea Arabica L }\end{array}$ & Creme & $\begin{array}{l}\text { Aumenta a expressão } \\
\text { mRNA de aquaporinas } 3\end{array}$ & Hamam ; Mira, 2016 \\
\hline $\begin{array}{c}\text { Água mineral } \\
\text { da fonte Alvorada }\end{array}$ & Solução & $\begin{array}{l}\text { Aumento da expressão } \\
\text { das aquaporinas } 3\end{array}$ & $\begin{array}{c}\text { Nunes; Tamura, } \\
\text { 2OII }\end{array}$ \\
\hline Gliceril glicosideo & Solução & $\begin{array}{l}\text { Aumento da expressão } \\
\text { das aquaporinas } 3 \mathrm{em} \\
\text { queratinócitos }\end{array}$ & Schrader, et al. 2012 \\
\hline Ácido retinoíco & Solução & $\begin{array}{l}\text { Aumento da expressão } \\
\text { das aquaporinas } 3 \mathrm{em} \\
\text { queratinócitos }\end{array}$ & $\begin{array}{l}\text { Xing et al., 20I6; } \\
\text { Hamam e Mira, } \\
\text { 20I6 }\end{array}$ \\
\hline Framboesa & $\begin{array}{c}\text { Extrato } \\
\text { lipossolúvel }\end{array}$ & $\begin{array}{l}\text { Aumente da expressão } \\
\text { dos genes das } \\
\text { aquaporinas } 3\end{array}$ & Tito et. al., 2015 \\
\hline Centella asiatica & $\begin{array}{c}\text { Extrato } \\
\text { etánolico } \\
\text { encapsulado }\end{array}$ & $\begin{array}{l}\text { Aumento da expressão } \\
\text { de aquaporinas } 3 \mathrm{em} \\
\text { queratinócitos }\end{array}$ & $\begin{array}{l}\text { YULIANT, et al,. } \\
2016\end{array}$ \\
\hline
\end{tabular}

Fonte: Próprio autor, 2021.

De acordo com os ativos analisados em sua grande maioria são extraídos de plantas e possuem a capacidade de aumentar a expressão de AQP 3 nas células dos queratinócitos. A rosa chinesa (Rosa chinenses) espécie de rosa natural nativa da China, possuiu em seu extrato um fito complexo rico em polissacarídeo que demonstrou eficiência para a hidratação da pele, tanto no uso tópico, quanto sistêmico, aumentando a expressão das aquaporinas 3 (PRESSI, et. al., 2019).

A Semente de chia (Salvia hispanica L.) constitui uma rica fonte de ácidos graxos, ômega 3 e vitamina $\mathrm{F}$ que comprovou desempenhar um papel importante na manutenção da função da pele através do aumento da expressão das aquaporinas 3 em queratinócitos em uso tópico (HUBER, et. al., 2020).

O alcaçuz (Glycyrrhiza) espécie rica em saponinas, flavonoides, isoflavonas, cumarinas estilbenóides, possuiu como composto bioativo o ácido I8ß-Glicirretínico um triterpeno que demostrou importante papel na biologia da pele em estudos in vitro, através da regulação da expressão do mRNA de aquaporinas 3 em fibroblastos dérmicos primários 
humanos, quando utilizando uma solução do ácido I8ß-glicirretínico o,oı\% (volume $30 \mu \mathrm{M}$ ) após um período $6 \mathrm{~h}$ de exposição (HUNG et. al., 2017).

Segundo Hamam e Mira (2016), outro ativo que vem sendo amplamente utilizado nas formulações cosméticas é o óleo da Semente de Green Coffea Arabica L. devido seu potencial para aumentar a expressão de mRNA das aquaporinas 3 em queratinócitos trazendo como benefícios restauração da umidade e hidratação da pele deixando-a com uma aparência mais jovem e firme.

A Framboesa (Rubus idaeus) ativo rico em ácidos graxos essenciais, apresentou capacidade de estimular a expressão das aquaporinas $3 \mathrm{em}$ até $32 \%$ nos testes in vitro em cultura de queratinócitos, auxiliado na formação da película hidrolipídica da pele, necessária para manter a integridade da epiderme e aumento da hidratação, efeitos confirmados também em estudos in vivo com 20 voluntarias com idade entre 20 e 60 anos produziu um efeito hidratante significativo na pele quando aplicado a curto prazo ( 7 horas), chegando a um aumento de 19\% quando aplicadas a longo prazo (28 dias) (Tito et al., 2015).

Centella asiatica rica em triterpenos é uma espécie frequentemente encontrada na Indonésia que demostrou através de estudos in vitro em exposição no período de 24 horas quando encapsuladas em nano partículas de quitosana induziu a expressão das aquaporinas 3 em até I,6 vezes, expressando a sua atuação na hidratação pele e grande potencial para formulações de cosméticos antienvelhecimento (YULIANT, et al,. 2016)

Dessa forma, é possível afirmar que estes ativos agem de forma profunda, melhorando a irrigação de água e hidratação cutânea, evitando o aparecimento de linhas de expressão e os sinais do processo de envelhecimento, mantendo a boa expressão da pele. Estes cosméticos são testados para comprovação de sua eficácia, podendo ser testes "in vivo" ou "in vitro", desse modo garantindo nas formulações cosméticas importantes benefícios para a hidratação da pele.

\section{CONCLUSÃO}

Com base no estudo realizado, podemos afirmar que aquaporinas 3 são canais proteicos que transportam água e estão localizados na membrana celular dos queratinócitos. Ao contrário do que se menciona na mídia, não existem aquaporinas dentro dos cosméticos, 
tratam-se de ativos extraídos de plantas ou sintetizados em laboratórios para aumentar sua expressão, agindo nas células pouco irrigadas e desidratadas devido ao envelhecimento cutâneo.

Estes ativos em cosméticos são usados com objetivo de controlar o aparecimento de linhas de expressão e a desidratação da pele, melhorando a aparência. Podemos concluir que, a descoberta das aquaporinas 3 e ativos que conseguem aumentar a sua expressão, trouxe um avanço significativo para a tecnologia dos cosméticos contra o envelhecimento, promovendo hidratação profunda contra desidratação, manutenção e a integridade das camadas da pele. Porém, a hidratação não depende apenas das aquaporinas, mas da manutenção dela em conjunto com outros fatores que ajudam na estabilidade da barreira cutânea.

Em relação aos malefícios relacionados aos ativos cosmeticos, percebe-se que ocorrem da mesma forma que os demais componentes de hidratantes em geral, quais sejam, possíveis processos alérgicos, como dermatite de contato devido a conservantes e corantes, sendo necessário testes alérgicos, como a observação de uma pequena quantidade em determinada área para o uso.

\section{REREFÊNCIAS}

AMARAL, Karina; SOUZA, Rafaela. Importância da Hidratação Cutânea para melhor tratamento das Disfunções Estéticas, Revista Multidisciplinar e de psicologia. 13, N. 48 p. 763-771, 2019.

BOLLAG et al. Aquaporin3 in the epidermis: more than skin deep. Am J Physiol Cell Physiol, 2020.

COSTA et al. Estudo clínico multicêntrico para avaliação de segurança e eficácia clínica de um hidratante corporal à base de ceramidas, ômegas, glicerina, Imperata cilíndrica, erythritol e homarine. Surgical \& Cosmetic Dermatology. V. 6, n. I, p.32-38, 2014. Disponível em:< https://www.redalyc.or g/pdf/265 5/265530997016. pdf >. Acessado em: 04.Nov.2020.

DRAELOS, Zoe. Aquaporins: an Introduction to a Key Factor in the Mechanism of Skin Hydration. The Jounal of Clinical and Aesthetic Dermatolog y, 2012.

GÓMEZ, Giovana; IRUSTA, Miriam. Acuaporinas y Piel. Universidad de Sevilla, 2014. 
HAMMAM, Moustafa; MIRA, Rasha. Aquaporin in Healthy and Diseased Skin. Advances in Environmental Biology. V. Io, n .I, p. 237-249, 2016.

HUBER, et al. HYVI: A novel, topical chia seed extract that improves ski n hydration. Journal Cosmet Dermatol, 2020.

HUNG, et al. I8ß-glycyrrhetinic acid derivative promotes pro liferation,migration and aquaporin-3 expression in human dermal. PLoS ONE, 2017.

IKARASHI, et al. Relationship between Aging-Related Skin Dryness and aqu aporins. International Journal of Molecular Sciences, 2017.

JUNGERSTED, et al. In vivo studies of aquaporins 3 and io in human stratum corneum. Archives of Dermatological Research, V.305, p.699-704, 2013.

KAMIZATO, Karina Kiyoko; BRITO, Silvia Gonçalves. Técnicas estéticas faciais. Editora Saraiva. I ed. São Paulo, 20I4.

NUNES, Samanta; TAMURA, Bhertha .Avaliação bioquímica e toxicológica de uma água mineral brasileira e seus efeitos cutâneos em uso tópico. Surgic al \& Cosmetic Dermatology, V.3, n. 3, p. 197-202, 2011.

PRESSI, et al. Rosa chinensis in vitro cell cultures: a phytocomplex rich of medium molecular weight polysaccharides with hydrating properties. Natural Product Research, 2019.

SCHRADER, et al. Effects of Glyceryl Glucoside on $\mathrm{AQP}_{3}$ Expression, Barrier Function and Hydration of Human Skin. Skin Pharmacol Physiol, V. 25, p.192-199, 2012. PRESSI, et al. Rosa chinensis in vitro cell cultures: a phytocomplex rich of medium molecular weight polysaccharides with hydrating properties. Natural Product Research, 2019.

STANDNICK, Táiná Delino; MÜLLER, Simony Davet. Estudo dos ativos cosméticos vegetais de uso profissional utilizados no envelhecimento facial. Universidade do Sul de Santa Catarina, 2019.

TITO, et, al. An oil-soluble extract of Rubus idaeus cells enhances hydration and water homeostasis in skin cells. International Journal of Cosmetic Science, V. 37, p 588-594, 2015. 
XING, et al. Effect of retinoic acid on aquaporin 3 expression in keratino cyte s. Genetics and Molecular Research, v. I5 n.I, 2016

YULIANTI, et al. Effects of Centella asiatica Ethanolic Extract Encapsulated in Chitosan Nanoparticles on Proliferation Activity of Skin Fibroblasts and Keratinocytes, Type I and III Collagen Synthesis and Aquaporin 3 Expression In vitro. J Pharm Biomed Sc, V. 6, n. 5, P 315-327, 2016. 